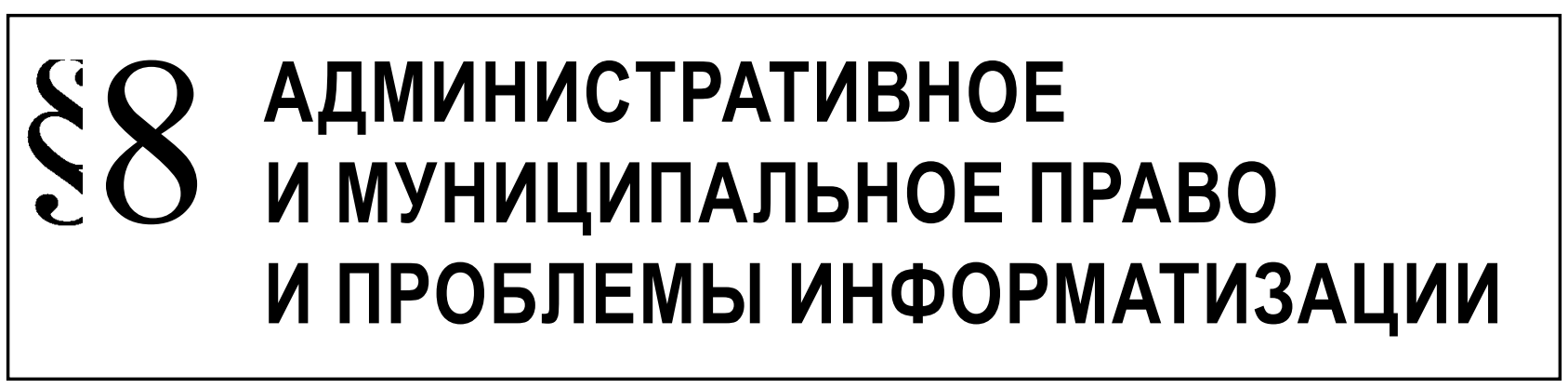

Шельменков В.Н.

\title{
ПРАВОВОЕ ОБЕСПЕЧЕНИЕ ДОСТУПА К ОФИЦИАЛЬНОЙ ИНФОРМАЦИИ В ГЕРМАНИИ
}

\begin{abstract}
Аннотация: В статье рассматривается доступ граждан и организаций к официальной информации о деятельности государственных органов в Германии, а также что каждый имеет право на получение и ознакомление с официальными документами. В Германии указанные правовые компоненты присутствуют в Основном законе Германии. Рассматриваются принципы и способы обеспечения доступа к информации, формы ее предоставления, права и обязанности пользователей информации, органов власти, их должностных лиц. Говорится о доступе к информации о деятельности органов власти в базах данных, на DVD, в журналах и электронной форме. Также информация может размещаться в СМИ, на стендах помещений, где органы власти осуществляют свою деятельность, в библиотечных и архивных фондах и т.д.Освещается процедура предоставления информации по запросу пользователя, включая требования к запросу о получении информации, сроки и порядок его рассмотрения, требования к ответу на запрос. Автором проведен анализ нормативного правого регулирования, а также судебной практики обеспечения доступа граждан к официальной информации в Германии В Германии присутствуют разные источники правовой информации. Они делятся на частные и государственные. Доступ к законам и правовым актам осуществляется на основе публикации законов в Федеральном вестнике законов. В связи с изложенным автор полагает, что не все граждане имеют свободный доступ к официальной информации в Германии.

Ключевые слова: Доступ, информация, право, германия, правовая информация, правовой акт, административный акт, органы государственной власти, источники правовой информации, опубликование.

Review: The article considers the citizens' and organisations' access to the information about the activities of state structures in Germany; it claims that everyone has the right to access to official documents. In Germany the components mentioned are contained in the General Law of Germany. The article considers the principles and ways of data access privision, the forms of granting, the rights and responsibilities of users of the information, the state authorities and their officials. The article considers the access to the information about the state structures activities in databases, on DVDs, in journals and in electronic form. The infornation can also be transmitted through the media, put on the stands in the rooms where the state authorities act, stored in libraries and archive collections, etc. The study deals with the issues of data access on user's demand including the demand requirements, the terms and the order of a demand consideration, the requirements to the reply on the demand. The author analyzes the normative legal regulation and the judicial practice of official data access provision in Germany. There are different sources of official information in Germany. They can be divided into private and state. The access to laws and legal acts is granted through the publication of laws in the Federal bulletin of laws. The author supposes that not all the citizens have a free access to the official information in Germany.

Keywords: access, information, right, Germany, legal information, legal act, administrative act, state structures, legal information sources, publication.
\end{abstract}

\footnotetext{
$\Gamma$ осударственная политика в отношении доступа к официальной информации в Германии, основывается на следующих конституционных положениях:
}

1. Все государственные органы связаны обязанностью соблюдения основных прав, в т.ч. чести и достоинства, прав человека (ст.1 и ст.20 Основного закона Германии). Соблюдение основных прав 
определяет обязанность органов государственной власти к публикации правовых норм (ст.82 Основного закона Германии).

2. Доведение правовых актов до всеобщего сведения должно отвечать требованиям абз. 1 ст.3 Основного закона Германии, а именно принципу равноправия (неоднозначное получение информации гражданами ведет к неадекватным возможностям с точки зрения отношения граждан к своим правам и их реализации).

3. Основной закон Германии устанавливает право граждан контролировать законопроектную деятельность, а также осуществлять контроль за деятельностью исполнительных органов по реализации законодательных положений и т. д. (абз.1 ст.42, ст.43, ст.44, ст.46, ст.52, ст.114, ст.115, ст.145).

4. Важную роль играют положения ст. 5 Основного закона Германии, в соответствии с которыми средства массовой информации имеют право получать сведения из всех общедоступных источников.

5. Абзац 1 ст. 20 Основного закона Германии, устанавливает принцип социального государства (дефицит информации, как правило, присутствует в более низких социальных слоях населения, что затрудняет государственные усилия в социальной области).

Наряду с этим на существующую систему, т.е. на действия государства, важное влияние оказывает судебная практика. Приведем несколько примеров.

а) Опубликование правовых актов представляет собой принцип правового государства. Опубликование является неотъемлемая часть правового акта. Право есть опубликованное право.

б) Опубликование правовых актов способствует установлению принципа надежности права: гражданам должна быть предоставлена возможность, распознавать, какие границы их свободы устанавливает тот или иной закон.

Закон «0 регулировании доступа к информации федерального правительства» ${ }^{1}$ был принят в июне 2005 года и вступил в силу 1 января 2006 года. Закон дает каждому право доступа к официальной информации, находящейся в распоряжении учреждений федерального правительства, либо организаций или частных лиц, исполняющих государственные функции. Информация должна предоставляться в течение одного месяца после подачи

\footnotetext{
Gesetz zur Regelung des Zugangs zu Informationen des Bundes (Informationsfreiheitsgesetz - IFG) http://www. informationsfreiheit.info/files/foia_ger many_final_june05_ clear.pdf(неофициальный перевод окончательного проекта).
}

запроса. Ответ может быть предоставлен в устной форме, письменно или в электронном виде. ${ }^{2}$

Как известно, указанное право отвечает следующим критериям: право доступа не связано с наличием правомерного интереса; предоставляется всем лицам, т.е не только гражданам соответствующего государства; устанавливает равенство доступа независимо от принадлежности той или иной группе пользователей; определяет сроки для предоставления информации со стороны исполнительных органов; подлежит ограничениям только с точки зрения охраны правомерных общественных интересов (национальная безопасность, общественный правопорядок и т.д.), защиты частной сферы и иных частных интересов; все отказы от предоставления информации должны быть обоснованы и могут быть обжалованы в судебном порядке.

Таким образом, указанное право объединяет в себе несколько правовых компонентов, а именно принцип свободы информации, право на информацию, включая право на получение и ознакомление с официальными документами. В Германии указанные правовые компоненты присутствуют в Основном законе Германии. Абзац 1 ст. 5 гласит: «Каждый имеет право свободно выражать и распространять свое мнение устно, письменно или визуально и беспрепятственно получать информацию из доступных источников». Тем не менее, это фундаментальное право на свободу информации не означает, что отдельные граждане имеют свободный доступ к информации государственных органов.

В Германии допускается информационный плюрализм источников. Не вызывает сомнений, что для Германии, прежде всего, существует различие между двумя основными видами источников правовой информации: частными и государственными. Государственные - неоднородны по своему правовому качеству. Часть их них является общедоступными в силу действующих принципов государственного устройства Германии: правовое государство, социальное государство, международные обязательства Германии перед другими государствами. Общедоступность таких источников правовой информации первично по отношению к действиям государства; речь идет, например, о

\footnotetext{
2 Примечание. В США Freedom of Information Act от 1996 г.; Сообщение Комиссии ЕС «Об общественном доступе к документации институтов и органов ЕС» от 08.06.1993 г.; Заявление государств-членов ЕС «О праве на доступ к информации»; иные документы Европейских сообществ. Также рекомендация Совета Европы от 1981 г. «Доступ к информации органов административного управления».
} 
протоколах заседаний парламента, законопроектах и законах, судебных решениях. Вторая часть источников характеризуется тем, что их общедоступность существует в случаях и объеме, устанавливаемых самим государством; здесь возникает субъективное право на допуск к правовой информации. К таковым относятся архивы, библиотеки и пр. В этом случае право на свободу информации в соответствии с абз. 1 ст. 5 Основного закона может быть реализовано только в объеме, гарантированным законом или иным актом.

Доступ к законам и правовым актам осуществляется на основе публикации законов в Федеральном вестнике законов (Bundesgesetzblatt), что предписывается Основным законом Германии (абз.1 ст.82), а также публикацией постановлений в указанном вестнике. Вопрос о публикации земельных законов регулируется в конституциях соответствующих земель (напр., ст. 71 Конституции земли Северный Рейн-Вестфалия). Публикация осуществляется в Бюллетене законов и постановлений ${ }^{3}$. Основной закон Германии использует понятия «официальная публикация» и «провозглашение». Провозглашение служит обеспечению правовой стабильности и осуществляется путем, установленным на конституционной основе, т.е. создает формальную веру в надежность права. Другое дело, что подобный подход не всегда способствует пониманию права; последнее, как правило, достигается иным способом через фактическое доведение до сведения общественности внутреннего содержания права (частные собрания законов и комментарии, книги, журналы и пр. на электронных и печатных носителях, радио- и телевещание). В отношение граждан, не обладающих юридическим знаниями, следует также заметить следующее: последние, хотя и обращаются к различным источникам информации, однако часто не в состоянии составить полное представление по конкретной, затрагивающей его интересы правовой проблеме; часто при этом негативную роль играет фактор времени, связанный с доступом к правовой

\footnotetext{
3 Право Германии различают законы в формальном смысле, т.е. акты, принятые парламентом в ходе законодательного процессе и правовые предписания, т.е. акты, направленные неопределенному числу адресатов и регулирующие всевозможные правоотношения, издаваемые высшими органами исполнительной власти во исполнение законодательных положений (правительством, министрами и пр.) на основании полномочий, устанавливаемых соответствующим законом (ст.80 Основного закона). Такие правовые предписания являются законами в материальном смысле.
}

информации и ее самостоятельным уяснением. В этом случает доступ к правовой информации суживается для гражданина пояснительной деятельностью адвокатов и иных лиц, профессионально занимающихся консультационной деятельностью в области права.

Особое место занимает вопрос о доступе к административным предписаниям, под которыми понимается правила, изданные вышестоящими органами государственного управления в процессе их деятельности в адрес нижестоящих в целях определения порядка осуществления последними своих функций. Порядок принятия административных актов регулируется федеральным законом об административном производстве и соответствующими земельными законами. Административное право Германии впервые получило законодательное закрепление понятия «административный акт» в 1948 году в абзаце 1 параграфа 25 Постановления Военного совета Британской зоны Германии № 165 (Abs. 1 §25 MRVO Nr. 165), регулировавшего подсудность административных судов.

Современное закрепление понятия административного акта содержится в предложении 1 параграфа 35 Закона об административном производстве Германии (S.1 §35 VwVfG) ${ }^{4}$ в котором под административным актом понимается любое распоряжение, решение или иное властное действие административного органа, направленное на урегулирование единичного случая в области публичного права и имеющее прямые правовые последствия внешнего характера. Как правило, органы государственного управления осуществляют подобную публикацию в Федеральном регистре, при этом издания федеральных министерств также являются официальными ${ }^{5}$. Количество выпускаемых официальных изданий в Германии велико и обильно, что вполне отражает федеративную структуру государства с большим числом общественных организаций и институтов. Фактически не существует ни контроля, ни координации такой издательской деятельности ни со стороны Федеральной и Земельной власти, ни со стороны других официальных органов, в том числе муниципальных.

Для того, чтобы получать информацию о деятельности правительства и формировать собствен-

\footnotetext{
4 Verwaltungsverfahrensgesetz 25.05.1976 /Электронный реcypc/ http://bundesrecht.juris.de/bundesrecht/vwvfg/gesamt.pdf

5 Официальное электронное опубликование: История, подходы, перспективы / Под ред. проф. В.Б. Исакова. - М.: Формула права, 2012. стр.22
} 
ное мнение, должны существовать определенные источники, имеющие отношение к официальным изданиям и правительственным документам и доступные гражданам, не предназначенные только для внутреннего использования по соображениям содержания или каким-либо другим юридическим причинам.

Наряду с этим в Германии в отношении административных актов сложилась следующая ситуация.

Во-первых, ст. 82 Основного закона Германии и соответствующие статьи конституций земель не отрицают возможность публикации административных положений в Федеральном вестнике законов или в земельных Бюллетенях законов и постановлений.

Во-вторых, в соответствии с Общим регламентом деятельности федеральных министерств подчеркивается, что Федеральный вестник является органом публикации административных актов, если посредством опубликования в министерских бюллетенях не может быть достигнут должный эффект доведения до всеобщего сведения. При этом опубликование в Федеральном вестнике законов и министерском бюллетене признается равнозначным.

В-третьих, особые официальные отчеты об информационной деятельности и обязательства федеральных и государственных правительственных органов признаются «нормативными» по решению Федерального Конституционного Суда от 02.03.1977 г. Принятие такого решения явилось следствием проблем связанных с участием Федерального правительства в общественной жизни во время предвыборной кампании. В частности, Федеральное правительство должно «принимать меры направленные на то, чтобы публикации правительства в области общественных отношений не касались участия в выборах политических партий или групп». В этой связи Суд, тем не мене, констатирует, что «участие Правительства и законодательных органов в общественной жизни в определенных границах является не только допустимым, но и необходимым». Это подтверждается Основным законом Германии создающего максимально возможный консенсус граждан и общества и основной обязанностью Правительства является претворение этого принципа в жизнь.

В-четвертых, ст.65 Основного закона Германии определяет, что каждый федеральный министр самостоятельно и под свою ответственность ведет дела своей отрасли. Из этого следует, что каждое министерство имеет определенные общественные связи и занимается издательской деятельностью, соблюдая ту же субординацию, что и федеральные учреждения, и органы на национальном уровне. Аналогичная структура существует в соответствующих институтах всех немецких федеральных земель.

Однако, хотел бы Вас обратить на один момент, что практика публикации в Германии придерживается теории «формальных адресатов», в соответствии с которой государство вправе решать, какие нормы и в отношении каких адресатов подлежат доведению сведения. Сказанное во взаимосвязи с понятием «общедоступные источники» ст.5 Основного закона Германии означает, что не все административные акты подлежат публикации.

В Германии официальные публикации распространяются разными путями. Некоторые можно заказать непосредственно у издающего органа, другие можно приобрести в торговой сети. Некоторые - бесплатно, другие за небольшую плату. Параллельно с традиционными физическими формами, официальные издания все больше публикуются в электронном виде на CD, DVD, а также выставляются в Интернете. Органы государственной власти обязаны вести каталоги информации с указанием ее целевого назначения. Каталоги и другая информация должны предоставляться на правительственных веб-сайтах.

В Германии отсутствует обычная «система Федерального и Земельного законодательства, которые регулируют поставку обязательных экземпляров в соответствующие библиотеки. На сегодняшний день отсутствуют закон об обязательном экземпляре.

Следующий этап составляет доступ к судебной информации.

Основные принципы государственной политики заключаются в следующем.

- На федеральном уровне не существует какихлибо законов, обосновывающих обязанности федеральных судов по публикации принятых решений - за исключением обязанности федерального конституционного суда опубликовывать свои решения в Федеральном вестнике законов, основание: абз.2 параграф 31 Закона о Федеральном конституционном суде.

- На земельном уровне подобных законодательных положений также не существует - за исключением обязанностей опубликования отдельных решений в процессе проверки соответствия земельных правовых норм федеральному регулированию, основание: ст.100 Основного закона Германии. 
- Наряду с этим в отдельных землях Германии существуют директивы или предписания органов земельной исполнительной власти, в т.ч. в земле Северный Рейн-Вестфалия - циркуляр министерства юстиции от 18.03.1993 г. «Передача текстов судебных решений третьим лицам», в земле Гессен - инструкция министерства юстиции «Публикация судебных решений» от 27.03.1990 г., в земле ШлезвигГольштейн - общее распоряжение министра юстиции от 01.03.1993 г. «Директива о сотрудничестве органов юстиции со средствами массовой информации». Указанные положения регулируют главным образом вопросы, связанные с защитой данных, содержащихся в судебных решениях.

И наконец, из абзаца 1 ст.5 Основного закона Германии косвенным образом можно вывести общую обязанность судебных органов как можно более широко опубликовать судебные решения.

Доведение судебных решений до общественности происходит двумя путями. Во-первых, через сами судебные органы. При каждом судебном органе Германии существуют отделы «работы со средствами массовой информации» или пресс-службы, в обязанность которых входит выдача сообщений прессе, главным образом, в отношении рабочего плана суда и по принятым решениям.

Во-вторых, судебные органы передают право на публикацию своих решений печатным издательствам или производителям информационных технологий. Основная часть судебных решений выходит в свет несколькими способами: в виде сборников судебных решений, в электронных банках данных, на DVD, и в журналах. Предоставление судебных решений осуществляется как в в печатной, так и в электронной форме (напр. в СПС Juris)

Исходя из сказанного выше, основные возможности доступа к информации судебных органов можно описать следующим образом:

1) можно получить из сообщений судебных органов прессе со стороны суда;

2) передача судебными органами судебных решений для опубликования на основе соответствующего договора;

3) передача судебными органами собственных решений для опубликования на основе запроса со стороны издательства без наличия соответствующего договора;

4) предоставление материалов адвокатами или сторонами судебного процесса;
5) новости, распространяемые информационными агентствами;

Для опубликования судебных решений существуют некоторые специальные ограничения, а именно с точки зрения защиты персональных данных. Регулирующими положениями здесь являются: Федеральный закон о защите информационных данных, а также соответствующие земельные законы ( напр., закон о защите информационных данных земли Баден-Вюртемберга, закон о защите информационных данных Баварии и т.д.) Немецкое право не устанавливает обязанность судов опубликовать свои решения. В результате немецкие суды сами устанавливают, какие из принятых ими решений представляют интерес для публикации, при этом главную роль играет значение того или иного судебного прецедента для развития национального права. Сказанное относится для судов всех уровней. На их основании опубликование судебных решений в полном объеме не предоставляется возможным. В результате решения судов Германии доступны пользователю в обработанной (анонимной) форме, которая отличается от оригинала' ${ }^{6}$ Все опубликованные решения немецких судебных инстанций являются неполными. Другое дело, что доведение до всеобщего сведения может происходить различными способами: текст судебного решения за исключением персональных данных (так называемый «полный текст»), только резолютивная часть решения (так называемый «неполный текст») и тезисы решения. Типовой формы как таковой не существует, однако суды придерживаются некоторой схемы, сложившейся на практике, например:

1. Производство - компетенция суда - основание

2. Производство - иск - содержание

3. Европейское экономическое сообщество - сущность - права и обязанности отдельных лиц.

4. Государства-члены - обязанности - нарушение - национальный суд

В заключение некоторые примечания в отношении авторских прав, что оказывает свое влияние на объем и состав правовой информации, предлагаемой производителями электронных банков данных и издательствами (напр., лицензионное приобретение у издательств прав на включение в электронные банки данных комментариев, собраний судебных решений или собраний законо-

\footnotetext{
6 Опубликование решений Суда ЕС, Европейской комиссии по правам человека и судов некоторых иных государств, напр., США осуществляется в полном объеме.
} 
дательных актов, которые пользуются высоким спросом, фактически невозможно).

Законы, постановления, государственные указы и заявления, тексты и официальные тезисы судебных решений не подпадают под действие положений авторского права (абз.1 параграф 5 Федерального закона об охране авторских прав) ${ }^{7}$. Сказанное также относится к иным официальным документам в общественных интересах.

Деятельность Федеральных архивов осуществляется на основе Федерального закона»Об архивах» ${ }^{8}$.Данный Закон дает право открытого доступа к большинству документов по истечении тридцати лет. Личная информация хранится в течение тридцати лет после смерти человека или 110 лет со дня его рождения. Доступ к информации может быть закрыт в соответствии с другими закона- ми. Правительство объявило в апреле 2006 года об открытии архивов, касающихся Холокоста.

Архивы предоставляют собой собрание материалов по закону об охране авторских прав и подлежат соответствующей защите. Понятие архива достаточно четко определяется в Общем регламенте деятельности министерств от 8 января 1958 г., учитывая тот факт, что право пользования федеральными и земельными архивами ограничено и приобретение полного архива официальных документов для распространения не представляется в Германии возможным. Также защите подлежат права авторов архивов (государственные служащие или третьи лица, внесшие особый вклад в составление архива), а также собственники частных собраний материалов, депонированных в общественных архивах.

\section{Библиография:}

1. Административное право: учебник / Б.В. Россинский, Ю.Н. Старилов.-4-е изд., пересмотр. и доп.-М. : Норма, 2009. С. 435 .

2. Административное право зарубежных стран: Учебник / под ред. А.Н. Козырина, М.А. Штатиной. М., 2003. С. 199

3. С.Н. Братановский, С.Ю. Лапин. Право на доступ к информации как элемент конституционного права на информацию "Гражданин и право", 2012, № 8.

4. Официальное электронное опубликование: История, подходы, перспективы / Под ред. проф. В.Б. Исакова. - М.: Формула права, 2012. стр. 22.

5. Право на доступ к информации. Доступ к открытой информации / Отв. Ред. И.Ю. Богдановская.-М.: ЗАО «Юстицинформ», 2009. - 344 с.

6. Свобода информации в мире 2006 г. / Общий обзор законодательства по доступу к правительственной информации в мире /ДЭВИД БАНИСАР.

7. Основной закон Федеративной Республики Германии от 23 мая 1949 года.

8. Закон «Об авторском праве и смежных правах» от 09.09.1965 г. (с изменениями от 17.12.2008).

9. Закон "О хранении и использовании документов федеральных архивов" (Bundesarchivgesetz-BArchG) от 6 января 1988 г. (BGBl. I S. 62), с последними изменениями и дополнениями, внесенными Законом "Освободе информации" от 5 сентября 2005 г. (BGBl. I S. 2722). http://www.bundesarchiv.de/benutzung/rechtsgrundlagen/ bundesarchivgesetz/index.html?lang=en

10. Gesetz zur Regelung des Zugangs zu Informationen des Bundes (Informationsfreiheitsgesetz - IFG) http://www. informationsfreiheit.info/files/foia_ger many_final_june05_clear.pdf(неофициальный перевод окончательного проекта)

11. Закон от 15 января 1988 г. Об охране и использовании Федеральных архивных записей (Закон о федеральных архивах) (Gesetz über die Sicherung und Nutzung von Archivgut des Bundes (Bundesarchivgesetz-BArchG));

12. Федеральный закон, устанавливающий общие положения для информационных о коммуникационных услуг (Закон об информационных и коммуникационных услугах (Federal Act Establishing the General Conditions for Information and Communication Services (Information and Communication Services Act));

13. Verwaltungsverfahrensgesetz 25.05.1976 /Электронный pecypc/ http://bundesrecht.juris.de/bundesrecht/vwvfg/ gesamt.pdf

\footnotetext{
7 Закон «Об авторском праве и смежных правах» от 09.09.1965 г. (с изменениями от 17.12.2008 г.)

8 Закон “О хранении и использовании документов федеральных архивов” (Bundesarchivgesetz - BArchG) от 6 января 1988 г. (BGBl. I S. 62), с последними изменениями и дополнениями, внесенными Законом “О свободе информации” от 5 сентября 2005 г. (BGBl. I S. 2722).

http://www.bundesarchiv.de/benutzung/rechtsgrundlagen/

bundesarchivgesetz/index.html?lang=en
} 


\section{References (transliterated):}

1. Administrativnoe pravo: uchebnik / B.V. Rossinskii, Yu.N. Starilov.-4-e izd., peresmotr. i dop.-M. : Norma, 2009. S. 435.

2. Administrativnoe pravo zarubezhnykh stran: Uchebnik / pod red. A.N. Kozyrina, M.A. Shtatinoi. M., 2003. S. 199.

3. S.N. Bratanovskii, S.Yu. Lapin. Pravo na dostup k informatsii kak element konstitutsionnogo prava na informatsiyu "Grazhdanin i pravo", 2012, № 8.

4. Ofitsial'noe elektronnoe opublikovanie: Istoriya, podkhody, perspektivy / Pod red. prof. V.B. Isakova. - M.: Formula prava, 2012. str. 22.

5. Pravo na dostup k informatsii. Dostup k otkrytoi informatsii / Otv. Red. I.Yu. Bogdanovskaya.-M.: ZAO «Yustitsinform», 2009. - $344 \mathrm{~s}$.

6. Svoboda informatsii v mire $2006 \mathrm{~g}$. / Obshchii obzor zakonodatel'stva po dostupu k pravitel'stvennoi informatsii v mire /DEVID BANISAR.

7. Osnovnoi zakon Federativnoi Respubliki Germanii ot 23 maya 1949 goda.

8. Zakon «Ob avtorskom prave i smezhnykh pravakh» ot 09.09.1965 g. (s izmeneniyami ot 17.12.2008).

9. Zakon "O khranenii i ispol'zovanii dokumentov federal'nykh arkhivov" (Bundesarchivgesetz-BArchG) ot 6 yanvarya 1988 g. (BGBl. I S. 62), s poslednimi izmeneniyami i dopolneniyami, vnesennymi Zakonom "Osvobode informatsii" ot 5 sentyabrya 2005 g. (BGBl. I S. 2722). http://www.bundesarchiv.de/benutzung/rechtsgrundlagen/bundesarchivgesetz/ index.html?lang=en

10. Gesetz zur Regelung des Zugangs zu Informationen des Bundes (Informationsfreiheitsgesetz - IFG) http://www. informationsfreiheit.info/files/foia_ger many_final_june05_clear.pdf(neofitsial'nyi perevod okonchatel'nogo proekta)

11. Zakon ot 15 yanvarya 1988 g. Ob okhrane i ispol'zovanii Federal'nykh arkhivnykh zapisei (Zakon o federal'nykh arkhivakh) (Gesetz über die Sicherung und Nutzung von Archivgut des Bundes (Bundesarchivgesetz-BArchG));

12. Federal'nyi zakon, ustanavlivayushchii obshchie polozheniya dlya informatsionnykh o kommunikatsionnykh uslug (Zakon ob informatsionnykh i kommunikatsionnykh uslugakh (Federal Act Establishing the General Conditions for Information and Communication Services (Information and Communication Services Act));

13. Verwaltungsverfahrensgesetz 25.05.1976 /Elektronnyi resurs/ http://bundesrecht.juris.de/bundesrecht/vwvfg/ gesamt.pdf 